\title{
ON A NEW GROUP OF POST-SARMATIAN BURIALS IN THE MIDDLE DON REGION ${ }^{1}$
}

\author{
Aleksandr P. Medvedev \\ Voronezh State University, Voronezh, Russian Federation \\ Valeriy D. Berezutskiy \\ Voronezh State Pedagogical University, Voronezh, Russian Federation
}

\begin{abstract}
The paper raises the question of a separate group of barrow burials following the classical Late Sarmatian culture in the Middle Don region. The recently excavated sites include a T-shaped catacomb discovered on the right bank of the Don River (Losevo). Most likely, it belonged to a Tanais Alan who survived the Hunnic massacre and moved off to the north, to remote areas of the Don region not affected by the Hunnic invasion. On the left bank of the Don River (Berezovka), we have studied undercut burials synchronous to the catacomb from Losevo, with the rite and grave goods continuing the Late Sarmatian traditions (type of burial structure, northward orientation of buried people, artificial skull deformation, remnants of sacrificial food in the form of sheep and goat bones, etc.). The ceramic complex of these burials includes Late Sarmatian and Central Caucasian moulded and pottery ware. A warrior's burial in barrow 9 near the village of Berezovka contained not only typical Late Sarmatian ceramics, but also coarse moulded ware most likely connected with more northern traditions. It could belong to the settled population of the Middle Khoper region that left the sites of the Inyasevo type. Both groups of burials contain some indicators (metal parts of horse harness, belt buckles, a Chernyakhov-type fibula) dating them back to the second half of the 4th - early 5th centuries AD. But at the same time they do not contain any specific features of the Hunnic culture. According to the traditional periodization, the above-mentioned complexes can be qualified as belonging to the final stage of the Late Sarmatian culture. However, we think that it is better to use such a definition as the 'post-Sarmatian age' (or 'postSarmatian horizon'). The analyzed barrow burials were immediately antecedent to the Hunnic-age burial grounds of the first half of the $5^{\text {th }}$ century AD in the Upper Don region (Zhivotinnoye, Ksizovo, Mukhino, etc.).

Key words: Middle Don region, forest steppe, Late Sarmatian culture, barrows, catacombs, Sarmatians, Tanais Alans.

Citation. Medvedev A.P., Berezutskiy V.D. On a New Group of Post-Sarmatian Burials in the Middle Don Region. Vestnik Volgogradskogo gosudarstvennogo universiteta. Seriya 4, Istoriya. Regionovedenie. Mezhdunarodnye otnosheniya [Science Journal of Volgograd State University. History. Area Studies. International Relations], 2018, vol. 23, no. 3, pp. 138-152. (in Russian). DOI: https://doi.org/10.15688/jvolsu4.2018.3.12
\end{abstract}

\section{О НОВОЙ ГРУППЕ ПОГРЕБЕНИЙ ПОСТСАРМАТСКОГО ВРЕМЕНИ НА СРЕДНЕМ ДОНУ ${ }^{1}$}

\author{
Александр Павлович Медведев \\ Воронежский государственный университет, г. Воронеж, Российская Федерация
}

\section{Валерий Дмитриевич Березуцкий}

Воронежский государственный педагогический университет, г. Воронеж, Российская Федерация

Аннотация. В статье ставится вопрос о выделении на Среднем Дону курганных погребений, следующих за классической позднесарматской культурой. Среди недавно раскопанных памятников есть катакомба 
T-образного типа, открытая в Правобережье Дона (Лосево). Скорее всего, она принадлежала алану-танаиту, уцелевшему после гуннского погрома и откочевавшему на север, в глубинные районы Подонья, не затронутые гуннским вторжением. В Левобережье (Березовка) исследованы синхронные лосевской катакомбе подбойные погребения, по обряду и инвентарю продолжавшие позднесарматские традиции (тип погребального сооружения, северная ориентировка погребенных, искусственная деформация черепа, остатки жертвенной пищи в виде костей мелкого рогатого скота и пр.). В керамическом комплексе этих погребений присутствуют лепные и гончарные сосуды позднесарматского и центральнокавказского производства. В воинском погребении кургана 9 у с. Березовка, помимо характерной позднесарматской керамики, была поставлена груболепная посуда, скорее всего, связанная с более северными традициями. Она могла принадлежать оседлому населению Среднего Прихоперья, оставившему памятники типа Инясево. Обе группы погребений содержат хроноиндикаторы (металлические детали конской упряжи, поясные пряжки, фибула черняховского стиля) второй половины IV - начала $\mathrm{V}$ в. н. э. Но в них еще нет никаких специфических признаков культуры собственно гуннов. Исходя из традиционной периодизации, представленные выше комплексы можно отнести к финальному этапу развития позднесарматской культуры. Однако, по мнению авторов, они больше соответствуют определению «постсарматское» время» (или «горизонт»). Проанализированные подкурганные захоронения непосредственно предшествуют грунтовым могильникам гуннского времени на Верхнем Дону первой половины V в. н. э. (Животинное, Ксизово, Мухино и др.).

В.Д. Березуцкий провел раскопки курганов у с. Лосево и Березовка, открыл и описал публикуемые погребения, подготовил иллюстративный материал. А.П. Медведев проанализировал погребения в курганах у с. Лосево и Березовка, определил их датировку, установил культурную принадлежность и место в системе позднесарматских древностей лесостепного Подонья.

Ключевые слова: Средний Дон, лесостепь, позднесарматская культура, курганы, катакомбы, сарматы, аланы-танаиты.

Цитирование. Медведев А. П., Березуцкий В. Д. О новой группе погребений постсарматского времени на Среднем Дону // Вестник Волгоградского государственного университета. Серия 4, История. Регионоведение. Международные отношения. - 2018. - Т. 23, № 3. - C. 138-152. - DOI: https://doi.org/10.15688/jvolsu4.2018.3.12

Недавно считалось, что верхнедонские могильники II - середины III в. н. э. завершают ранний железный век в Лесостепном Подонье. Однако в начале 90-х гг. прошлого века на р. Воронеж и Верхнем Дону были открыты поселения и могильники, по облику материальной культуры отличающиеся от местных городищ и курганов сарматского времени. Со временем стало ясно, что по своему происхождению они, прежде всего, связаны с черняховской и киевской культурами днепровского Левобережья [13, с. 11-24; 14, с. 235-246; 17, c. $148-156$ и др.]. Под влиянием этих открытий два десятилетия назад один из авторов предложил выделить в истории Верхнего Подонья постсарматский этап, под которым понимал время распространения здесь памятников второй половины III - середины V в. н. э. [12, с. 20-21]. Однако в последние годы на Среднем Дону экспедицией Воронежского государственного педагогического университета открыты курганные погребения, следовавшие за позднесарматскими могильниками.

Лосево (рис. 1, 1). В 2010 г. исследован курган 3 в могильнике у с. Лосево Павловс- кого района Воронежской области. Он имел насыпь полусферической формы диаметром 24 м и высотой 0,4 м. Под ней открыто единственное погребение в катакомбе (рис. 2). Поскольку оно опубликовано [6, с. 110-120], ниже мы приводим его краткую характеристику. Вокруг катакомбы располагалось кольцо могильного выкида из глины, сползающего к камере. В насыпи встречались кости животных, черепки битой гончарной посуды, у края могилы обнаружено скопление железных изделий, как минимум, от двух удил. В северозападном секторе насыпи найдена бронзовая бляха диаметром 3,8 см (рис. 2,1 ). Внутри ее круглой рамки находится звездообразная фигура с 13 лучами, образованными ажурными треугольниками, а в центре - отверстие диаметром 1,8 см. С внутренней стороны к бляхе припаяна дужка для крепления.

Погребение совершено в катакомбе Т-образной формы (рис. $2, a$ ). Входная шахта имела размеры $1,1 \times 2$ м. На ее дне были четыре ступеньки, которые вели в камеру, расположенную к северу от шахты. Камера овальной формы, размерами $1,6 \times 2,5$ м, ее пол залегал на 2,1 м ниже уровня материка. Перед входом в 
камеру в забутовке находился рог оленя со следами обработки (рис. 2, a (1)). На полу камеры лежал скелет мужчины тридцати лет вытянуто на спине, головой на ЗЮЗ, руки вдоль туловища, ноги прямые. У него отсутствовал череп, но сохранилась нижняя челюсть, найденная на 0,3 м выше уровня пола. Судя по всему, погребенный был положен головой на запад с небольшим отклонением к югу.

Вдоль северной стенки камеры в ряд поставлены пять сосудов (рис. 2, a (2-6)). Среди них сероглиняная гончарная кубышка с зооморфной ручкой (рис. 2,2 ). Она стояла на шелковой ткани малинового цвета (рис. $2, a$ (7)). Другой сосуд - гончарный двуручнылй кувшин с расширяющимся в верхней части горлом и шаровидным туловом (рис. 2,3 ). Третий сосуд - гончарный кувшин-двуручник с зооморфными ручками в виде стилизованного изображения коня с седлом (рис. 2, 4). Четвертый сосуд - узкогорлый гончарный чернолощеный кувшин без ручки с биконическим туловом, на днище которого концентрические окружности от подставки (рис. 2, 5). Пятый сосуд - лепной горшок с прямым горлом, яйцевидным туловом и плоским дном (рис. 2, 6). Слева от головы погребенного лежали кости мелкого рогатого животного (рис. 2, a (11)) вместе с железным ножом (рис. 2, 13). У левого плеча найдена железная подвеска в виде полого шарика на двух перевитых проволочках, разрушилась от коррозии (рис. 2, a (12)). На шелковой ткани находились две серебряные накладки наконечников ремней (рис. $2,7,8$ ). На левой части тазовых костей лежала бронзовая поясная пряжка (рис. 2, a (13)), рамка заметно утолщалась в месте наложения язычка с основанием, срезанным в виде уступа, его конец заходит за край рамки (рис. 2, 11). Вторая пряжка меньших размеров найдена на шелковой ткани (рис. 2, a (14)). Она того же типа, что и первая, но имела накладку полукруглой формы из свернутой вдвое медной пластинки на одной заклепке (рис. 2, 12). Здесь же находилось золотое изделие (рис. 2, a (16)), состоявшее из небольшой накладки, свернутой из тонкой золотой пластинки с двумя штифтами для крепления к коже или ткани, и двух перевитых проволочек с прямоугольными обоймицами на концах (рис. 2, 9). У правой тазовой кости ле- жала бусина из непрозрачного черного стекла (рис. 2, a (15)), украшенная пятнышками белого, зеленого и желтого цвета (рис. 2, 10).

По типу погребального сооружения, обряду и сопровождающему инвентарю комплекс принадлежит кругу катакомбных погребений Нижнего Дона второй хронологической группы [7, с. 286, 290-291, рис. 5, 2-3]. На это указывает, прежде всего, погребальное сооружение в виде Т-образной катакомбы под курганной насыпью. Весьма показателен набор посуды, среди которой есть сосуды, аналогичные северокавказской керамике с зооморфными ручками $[1$, с. $108-112$, рис. $67,2,3,9$; рис. $69,3,7,14]$, а также кувшины-двуручники [12, рис. 22, 7; рис. 43, 7]. Распространение подкурганных катакомбных погребений на Нижнем Дону связывают с аланами-танаитами Аммиана Марцеллина [4, с. 292]. Время катакомбного погребения в кургане у с. Лосево позволяют определить бронзовые пряжки, обладающие диагностическими признаками поясной гарнитуры второй половины IV в. н. э. $[9$, с. 196,203 , рис. $1, \Pi, 11]$. Бусина многоцветного стекла относится к так называемым крапчатым, которые ранее датировались весьма широко, а сейчас более определенно относят к гуннскому времени $[11$, с. $112-114$, рис. $115,15-18]$. Золотые накладки из тонкой перегнутой пластинки с гвоздиками для крепления известны у сарматов с I в. н. э., но также доживают до гуннского времени. Таким образом, по сочетанию этих находок, а также выразительному набору керамики погребение у с. Лосево, скорее всего, совершено ближе к концу IV века. Вполне вероятно, что оно могло принадлежать алану-танаиту, уцелевшему после гуннского погрома и откочевавшему в глубинные районы Подонья, не затронутые гуннским вторжением.

Березовка (рис. 1, 2). Курганный могильник 4 у с. Березовка Воробьевского района Воронежской области насчитывает до 20 задернованных насыпей. В 2017 г. экспедицией Воронежского государственного педагогического университета исследованы два кургана.

Курган 8. Диаметр его насыпи 10 м, высота не более 0,5 м. Под вершиной кургана открыто единственное подбойное погребение (рис. 3). Могильный выкид отсутствовал, так как он весь был сброшен во входную шахту и 
утрамбован. Прежде, чем описывать погребение, следует остановиться на находке под насыпью кургана металлических деталей конской упряжи, лежавших на погребенной почве в 2 м к юго-востоку от угла входной шахты.

Бронзовое кольия от удил диаметром $6,2$ см (рис. 4,1$)$. На нем два прямоугольных зажима из серебряных пластин размерами $1,5 \times 2,5$ см с парой заклепок для крепления ремней. Крупные дополнительные кольца удил с такими зажимами распространяются с III в., весьма характерны для IV в., но продолжают встречаться и в эпоху Великого переселения народов [10, с. 50].

Бронзовая ромбическая бляха, покрытая листовым серебром (рис. 4, 2). Верхний и нижний углы бляхи оформлены в виде округлых «ушек». По углам и в середине имеются отверстия, в некоторых из них сохранились заклепки для крепления к кожаной основе. Длина изделия до краев «ушек» 7 см, ширина 4,7 см, толщина до 2 мм. По аналогии с ромбическими бляхами из Старицы $60 / 1$ и Центрального VI 16/8 березовскую находку есть основания атрибутировать как конский налобник или наносник. Но, если вышеуказанные бляхи найдены в позднесарматских погребениях хронологических групп ІІа и ІІб [9, c. 207-208, pис. 4 Г, 5А], то можно допустить, что березовская фигурная бляха сложной формы типологически должна относиться к более позднему времени.

Бронзовые круглье, покрытые листовым серебром бляхи - три экземпляра (рис. 4, 3-5). Одна (видимо, центральная) имеет диаметр 6,5 см, две другие (боковые) - по 4 см. Основа всех блях, как и ромбического налобника, сделана из бронзы, покрытой тонким листовым серебром. При этом края серебряного листа загнуты за борт бронзового основания. Толщина этих блях 1,5-2 мм. Они также крепились к кожаной или деревянной основе посредством пяти серебряных заклепок длиной $0,7-0,8 \mathrm{~cm}$.

Серебряные бляшки - 10 экз. (рис. 4, б). Они полусферической формы, диаметром около 1 см при высоте 0,5 см. В центре - отверстие и заклепка для крепления к кожаной основе. Такие украшения узды получают распространение в комплексах хронологической группы ІІІа [9, с. 206-207, рис. 9Б, 4].
Серебряный наконечник ремня (рис. 4, 7). Изготовлен из пластины толщиной 1 мм, имеет прямоугольную форму, его окончание приострено. В основании наконечника есть круглое отверстие для крепления к ремню. Длина наконечника 4,1 cм, ширина 0,9-1 см.

Погребальное сооружение под курганной насыпью в виде подбоя с прямоугольной шахтой размерами $0,6 \times 1,8$ м, глубиной в материке 1,65 м (рис. 3). Она ориентирована по линии C-Ю. С запада к длинной стенке шахты примыкает овальная камера размерами $0,8 \times 2,1$ м. На органической подстилке лежал скелет взрослого человека, скорее всего, женщины, вытянуто, на спине, головой на север. Ее череп имеет признаки прижизненной деформации. В ногах обнаружен железный нож (рис. 3, 1; рис. 4, 9), а также горшок грубой лепки (рис. 3,2 ; рис. 4,8 ). У него короткий, отогнутый наружу венчик, яйцевидное тулово, плоское дно. По форме сосуд близок одному из типов позднесарматской лепной посуды [19, c. 28 , рис. 8,3$]$. Слева от грудной клетки погребенной найден фрагмент округлого деревянного прута диаметром 0,5 см, в который вбит бронзовый гвоздик (рис. 3, 4; рис. 4, 10). Тут же лежал кожаный шарик с отверстием, разрушившийся при извлечении (рис. 3, 3).

Тип погребального сооружения в виде подбоя, северная ориентировка погребенной, искусственно деформированный череп, а также лепной горшок и уздечный набор указывают на то, что погребение совершено согласно позднесарматской традиции. Металлические детали конской упряжи указывают на время ближе к финалу позднесарматской культуры.

Курган 9. Диаметр его насыпи 9 м, высота не более 0,2 м. Под вершиной обнаружено единственное погребение в виде подбоя (рис. 5). Могильным выкидом была забита входная шахта и камера. Шахта ориентирована по линии ЗЮ3-ВСВ, она узкая, углублена в материк на 1 м. С северо-запада к ней примыкает овальная в плане камера размерами $1,15 \times 2$ м. На органической подстилке лежал скелет мужчины, вытянуто, на спине, головой на востоко-северо-восток. У левой стопы найдена фибула (рис. 5,1 ), а на поясе пронизь из минерала (рис. 5,2 ). Между северо-западной стенкой могилы и погребенным находились железный меч (рис. 5, 3), кинжал 


\section{РАННИЙ ЖЕЛЕЗНЫЙ ВЕК}

(рис. 5, 4), а ближе к правой руке - каменный оселок (рис. 5, 5). Под плечевой костью этой же руки оказался верх лепного сосуда (рис. 5, б). Между юго-восточной стенкой и левым плечом погребенного найдены еще четыре сосуда: три лепных горшка (рис. 5, 7-9) и гончарная миска (рис. 5,10 ). Внутри миски обнаружены кости мелкого рогатого скота (рис. 5,11 ). Между грудной клеткой и плечевой костью левой руки лежал железный наконечник стрелы, который мог находится в теле погребенного (рис. 5, 12). Укажем, что у края с северо-восточной стенки шахты находились серебряный наконечник ремня и фрагментированное железное кольцо.

Бронзовая фибула с высотой спинки $6,2$ см (рис. 6,1$)$. Относится к двучленным прогнутым фибулам со сплошным приемником и узким кольцом для крепления пружинного аппарата. По заключению А.М. Обломского, в целом она выполнена в черняховском стиле, но от черняховских фибул отличается массивностью и наличием рельефного выступа на спин$\mathrm{\kappa e}^{2}$. Близкие черняховские фибулы относятся к типу I варианту 3 и датируют ступенями С2 D1 центральноевропейской хронологии, то есть в основном IV в. н. э. [18, с. 194].

Железный меч с узким лезвием длиной 50 см и шириной у рукояти 4 см (рис. 6,3 ). Виден плавный переход штыря рукояти в клинок, позволяющий отнести его ко 2 типу [20, c. 17,21$]$.

Короткий железный меч или кинжал с лезвием у рукояти шириной почти 5 см и длиной 40,5 см (рис. 6, 4). На месте рукояти сохранилась серебряная плоская круглая шайба диаметром 0,9 см с отверстием посредине и остатками железного гвоздика для крепления деревянной накладки на штырь рукояти. Формально этот клинок принадлежит тому же типу, что и более длинный меч. Обращает на себя внимание значительная ширина обоих клинков, что более характерно для более поздних мечей III-IV вв. [3, с. 181].

Каменный оселок (рис. 6, 5). Представляет собой брусок прямоугольного сечения $1 \times 1,5$ см длиной 16 см с отверстием для подвешивания. Подобные бруски хорошо известны по погребениям позднесарматского времени.

Пронизь (рис. 6, 2). Представляет собой круглое изделие из мела ${ }^{3}$ диаметром
2,1 см, толщиной 0,6 см с отверстием по центру. Подобные пронизи из меловой породы изредка встречаются в комплексах первых веков н.э. [2, с. 29 , табл. $44,11,48]$. Она могла использоваться в качестве детали портупеи.

Cосуд 1 у правого предплечья (рис. 6, б). Сохранился верх груболепного корчагообразного сосуда. Край венчика закруглен, не орнаментирован, тесто с примесью крупного шамота.

Cосуд 2 у черепа погребенного (рис. 6, 7). Груболепной горшок с отогнутым наружу венчиком и сильно выраженными плечиками. По составу теста практически идентичен сосуду 1 . По форме и фактуре горшок близок одному из типов лепной посуды с поселений типа Инясево-Шапкино на Среднем Хопре [20, c. 125 , фото справа], но отличается более подчеркнутыми плечиками.

Сосуд 3 к югу от сосуда 2 (рис. 6, 9). Горшок с коротким, отогнутым наружу венчиком, орнаментированным косыми вдавлениями, шаровидным туловом и плоским дном, он правлен на гончарном круге. Сосуд относится к IV типу позднесарматских горшков $[19$, c. 28 , рис. 8,4$]$, скорее всего, центральнокавказского производства. Горшки этого типа встречаются и в нижнедонских катакомбах IV в. н. э. [4, с. 289 , рис. 6,11$]$.

Сосуд 4 к югу от сосуда 3 (рис. 6, 8). Это фрагментированный груболепной горшок с отогнутым наружу венчиком, округлым туловом и плоским дном. Сосуд близок одному из типов позднесарматской лепной посуды, известной и по находкам в нижнедонских катакомбах второй хронологической группы IV в. [7, с. 289, pис. 6,10$]$, но отличается более грубой лепкой.

Сосуд 5 (рис. 6, 10). Гончарная миска с загнутым внутрь краем, местами видна подлощенная поверхность. Такие миски характерны для центральных районов Северного Кавказа III-IV вв. [1, с. 110 , рис. $67,21-24]$, откуда они попадали к поздним сарматам.

Железный наконечник стрелы плохой сохранности (рис. 6, 11). Длина наконечника 3,5 см, длина черешка 1,5 см. Относится к черешковым трехлопастным наконечникам, характерным для стрел как средне-, так и позднесарматского времени.

Серебряный наконечник ремня (рис. 6, 12). Он изготовлен из согнутой пополам тон- 
кой пластины с валикообразным окончанием и крепежом в виде двух штифтиков. Его размеры 1,1 × 1,2 см. Подобные наконечники получают распространение в позднесарматских погребениях группы ІІб, являются хроноиндикаторами нижнедонских катакомб первой группы [4, с. 288-289, рис. 4, 15; 9, рис. $8 \mathrm{~A}, 5-6$; рис. 10БІІ], хотя их находки известны в комплексах позднеантичных некрополей Боспора, где они доживают до последней четверти IV - первой половины V в. [8, с. 61 , табл. $28,129, a$, б].

Железное кольио (рис. 6, 13). Это рамка пряжки диаметром 2,3 см.

Таковы исследованные на сегодняшний день памятники археологии, позволившие поставить вопрос о выделении на Среднем Дону ранее неизвестной группы погребений рубежа древности и средневековья. Исходя из традиционной периодизации [19, с. 105-109], эти комплексы можно отнести к финальному этапу развития позднесарматской культуры или, скорее, к горизонту, непосредственно предшествующему наступлению гуннской эпохи. Надежные хроноиндикаторы гуннской эпохи появляются лишь в погребениях типа Новая Чигла (рис. 1,4$)$ [5, с. 219-243] и Подклетного (рис. 1,5 ), но особенно в верхнедонских грунтовых могильниках: Животинное (рис. 1, б), Ксизово 17, 19, Мухино (рис.1, 7) и др. [15, с. 38-74; 16, с. 134-164]. Если в среднедонском Правобережье пока известна одна катакомба, скорее всего, сооруженная для погребения алана-танаита, то в Левобережье (Березовка) явно доминируют позднесарматские признаки (подбойные захоронения, в том числе с северной ориентировкой и искусственно деформированными черепами, набор деталей упряжи из кургана 8, сосуды северокавказского производства из кургана 9.

Но помимо позднесарматского, в подбойных захоронениях Березовки просматривается и несарматский компонент - фибула черняховского стиля, а также набор груболепных сосудов. Такая керамика могла принадлежать какой-то группе лесостепного населения, возможно, потомкам «инясевцев» Среднего Прихоперья. На наш взгляд, на это косвенно указывает серия находок бронзовых фибул и металлических деталей поясной гарнитуры, недавно поступивших в Борисоглебский краеведческий музей (рис. 1, 3, - не опубликованы). Они явно происходят из грунтового могильника довольно узкого хронологического горизонта в пределах ступеней C2-D1 и могут являться свидетельствами продолжения оседлой жизни в Прихоперье в IV в. н. э.

\section{ПРИМЕЧАНИЯ}

${ }^{1}$ Исследование выполнено при финансовой поддержке РНФ, проект № 17-78-20048.

2 Авторы выражают признательность А.М. Обломскому за консультации по публикуемым металлическим изделиям и указанную им литературу, а также Е.Л. Гороховскому, который дал заключение о бронзовой фибуле из этого погребения, в целом совпавшее с атрибуцией А.М. Обломского.

${ }^{3}$ Определение ведущего сотрудника ГосНИИР, кандидата геолого-минералогических наук О.В. Аникеевой. 


\section{ПРИЛОЖЕНИЯ}

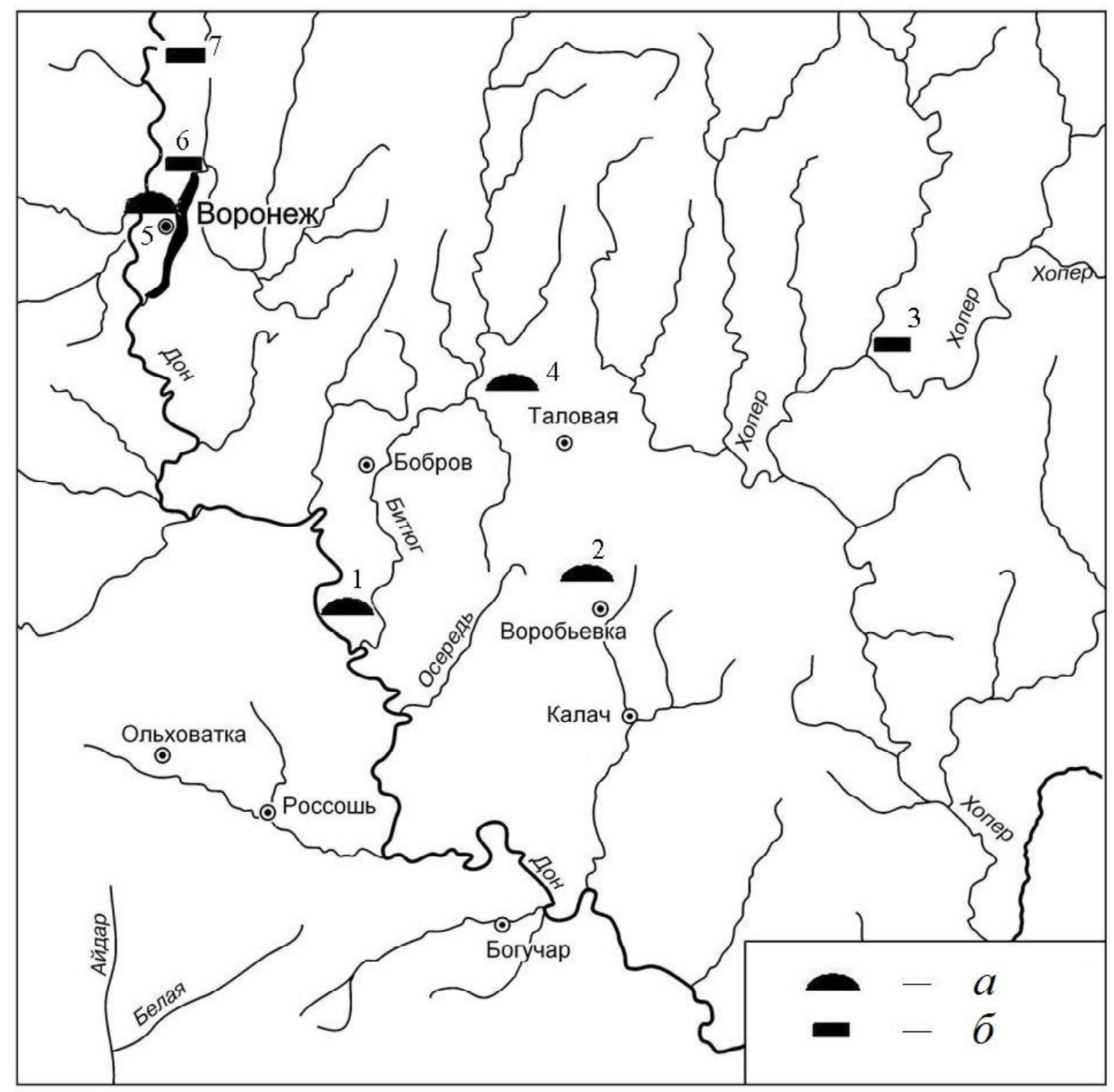

Рис. 1. Карта-схема основных погребальных памятников и находок постсарматского времени на Среднем и Верхнем Дону:

1 - Лосево; 2 - Березовка; 3 - Борисоглебск; 4 - Новая Чигла; 5 - Подклетное; 6 - Животинное; 7 - Ксизово, Мухино; $a$ - курганы; $\sigma$ - грунтовые погребения

Fig. 1. Sketch map of main Late Sarmatian burials and finds in the Middle and Upper Don regions: 1 - Losevo; 2 - Berezovka; 3 - Borisoglebsk; 4 - Novaya Chigla; 5 - Podkletnoe; 6 - Starozhivotinnoe; 7 - Ksizovo, Mukhino; $a$ - barrows; $b$ - ground burials 


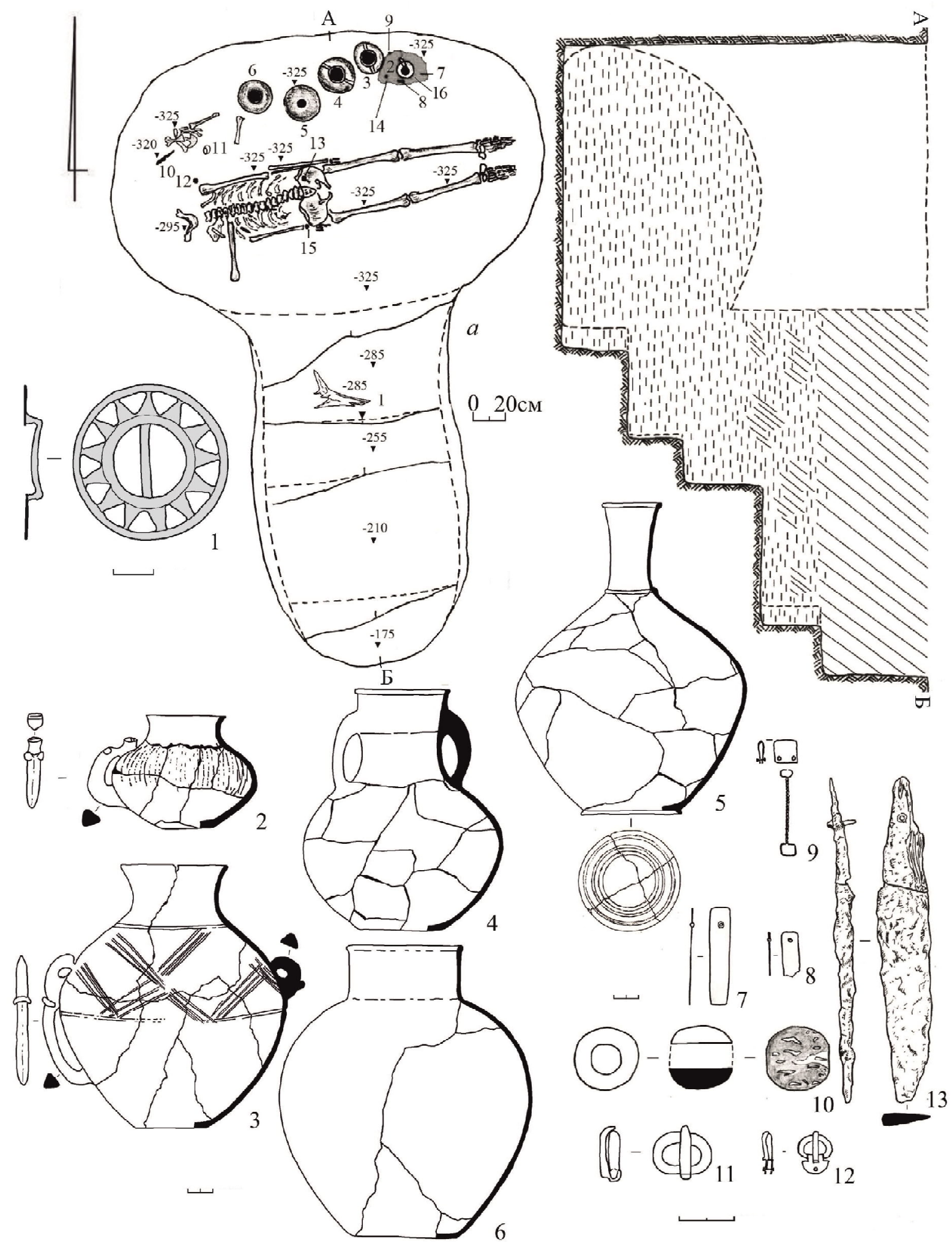

Рис. 2. Погребение в кургане у с. Лосево:

$a$ - план и разрез катакомбы; $1-13$ - сопровождающий инвентарь $(1,11,12$ - бронза; 2-6 - глина; 7-8 - серебро; 9 - золото; 10 - стекло; 13 - железо)

Fig. 2. A barrow burial near Losevo:

$a$ - plan and section view of the catacomb; $1-13$ - grave goods $(1,11,12$ - bronze; $2-6$ - earthenware; 7-8 - silver; 9 - gold; 10 - glass; 13 - iron) 


\section{РАННИЙ ЖЕЛЕЗНЫЙ ВЕК}

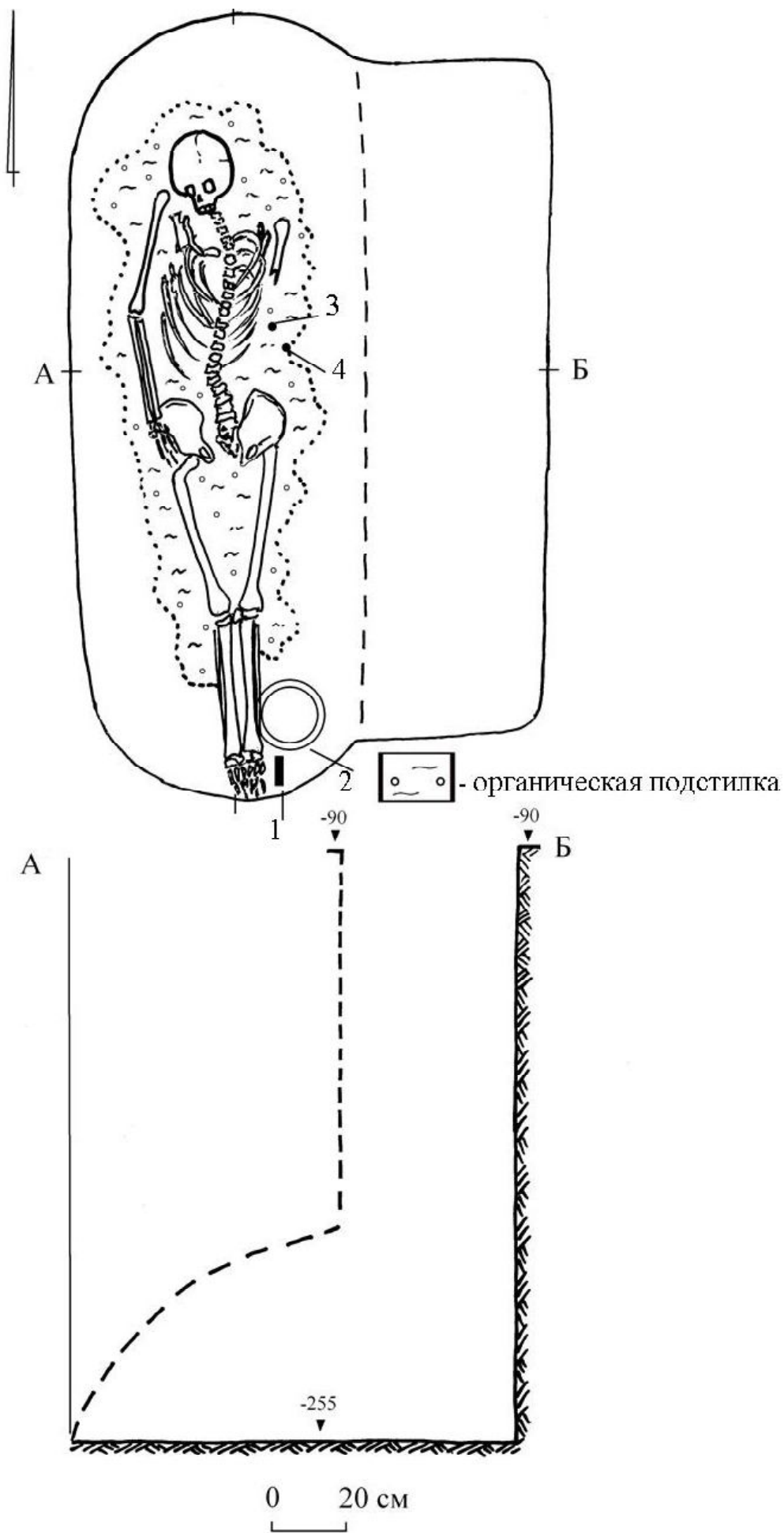

Рис. 3. Погребение в кургане 8 у с. Березовка. План и разрез подбойной могилы:

1 - железный нож; 2 - лепной сосуд; 3 - изделие из кожи; 4 - фрагменты деревянного изделия с бронзовым гвоздиком Fig. 3. Barrow burial 8 near the Berezovka village. Plan and section view of the cutting grave: 1 - iron knife; 2 - moulded vessel; 3 - leather item; 4 - fragments of a wooden item with a bronze nail 

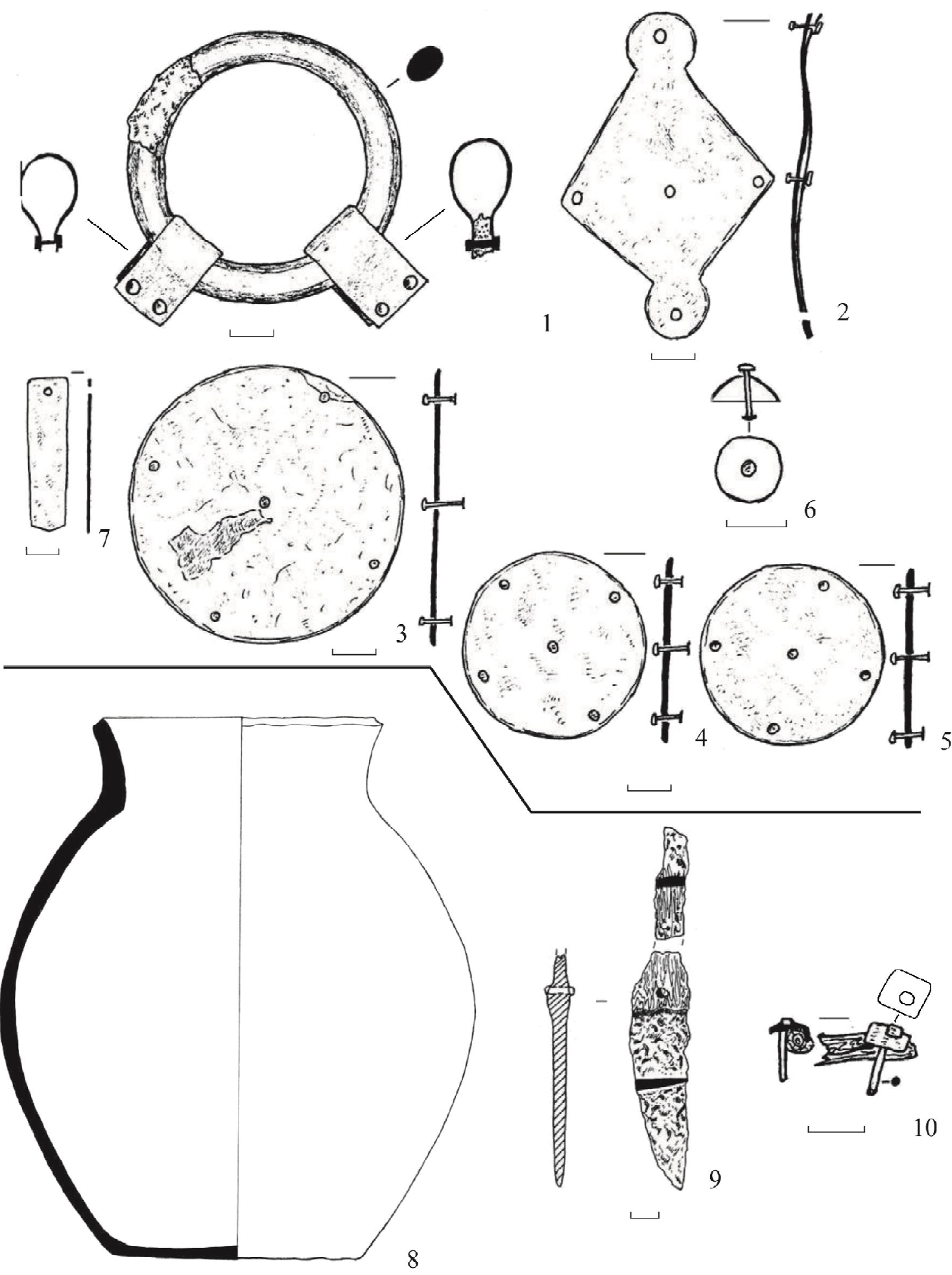

Рис. 4. Находки из погребения в кургане 8 у с. Березовка:

1-7 - под насыпью на уровне погребенной почвы (1-5 - бронза, серебро; 6-7 - серебро); $8-10$ - в подбойной могиле ( 8 - глина; 9 - железо; 10 - дерево, бронза)

Fig. 4. Finds from barrow burial 8 near the Berezovka village:

1-7 - under the mound, at the buried soil level (1-5 - bronze, silver; 6-7 - silver);

$8-10$ - in the cutting grave ( 8 - earthenware; 9 - iron; 10 - wood, bronze) 


\section{РАННИЙ ЖЕЛЕЗНЫЙ ВЕК}
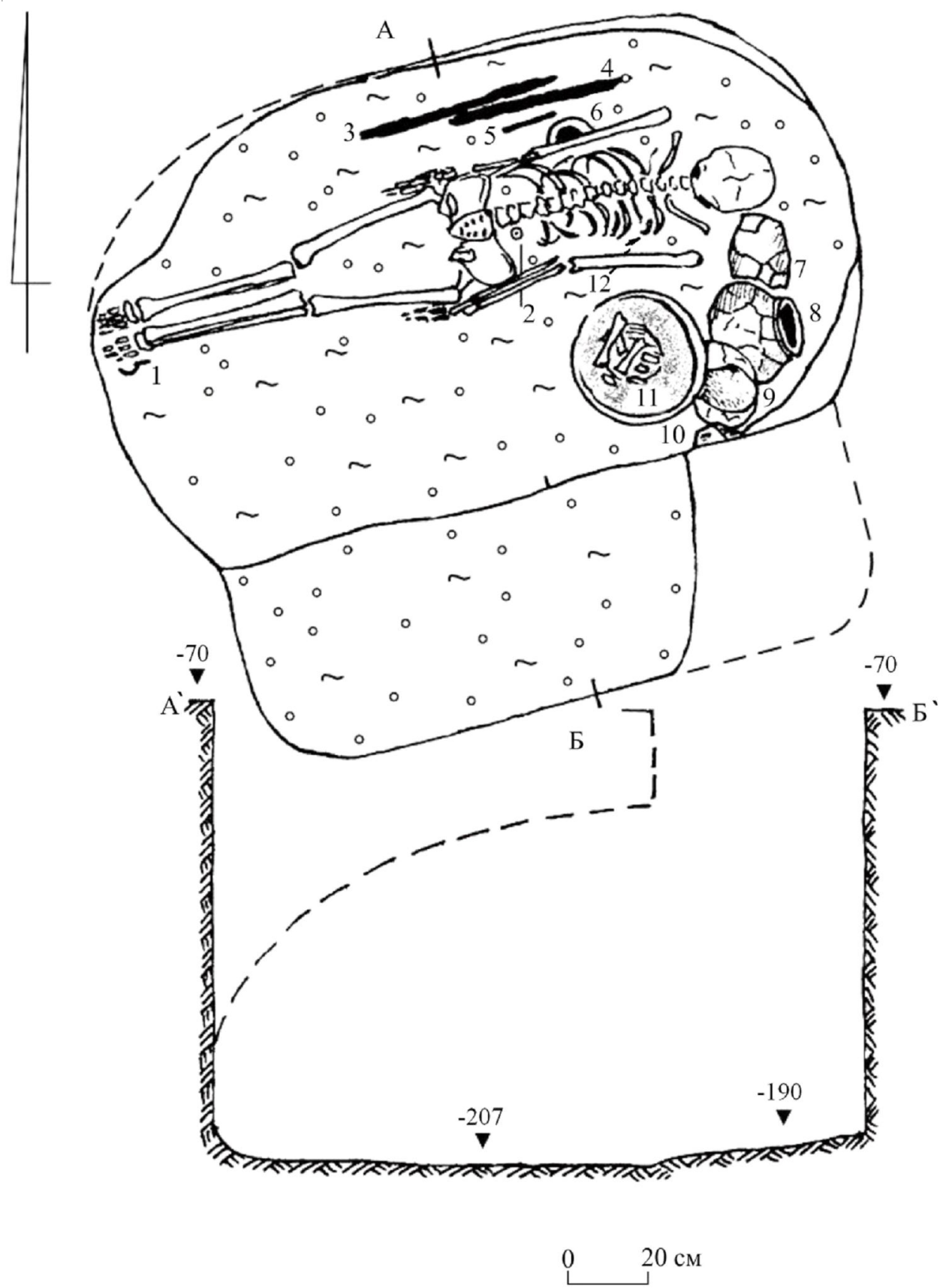

Рис. 5. Погребение в кургане 9 у с. Березовка. План и разрез подбойной могилы:

1 - фибула; 2 - пронизь; 3 - меч; 4 - кинжал; 5 - каменный оселок; 6-9 - лепные сосуды; 10 - гончарная миска; 11 - кости МРС; 12 - наконечник стрелы

Fig. 5. Barrow burial 9 near the Berezovka village. Plan and section view of the cutting grave:

1 - fibula; 2 - bead; 3 - sword; 4 - dagger; 5 - grindstone; 6- 9 - moulded vessels; 10 - pottery dish; 11 - bones of small cattle; 12 - arrowhead 

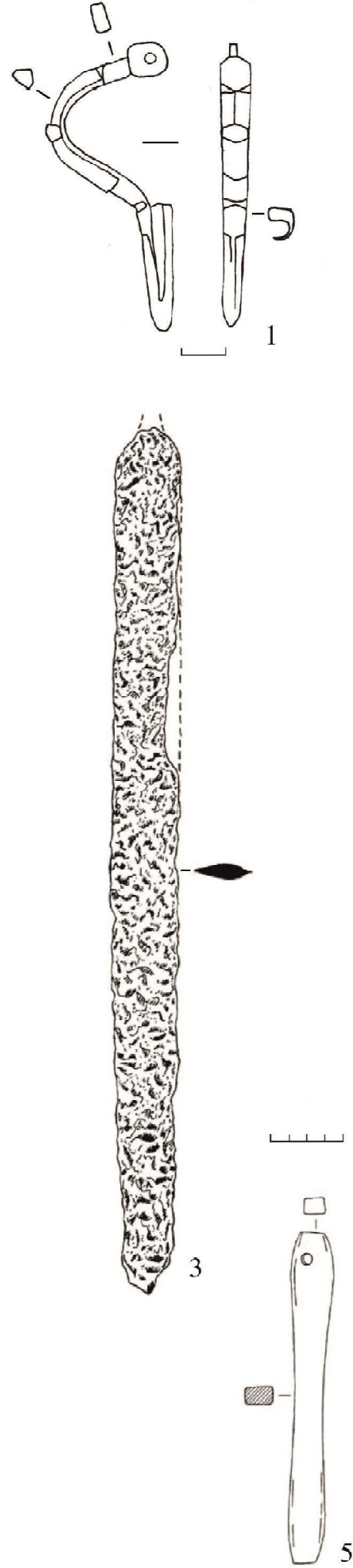
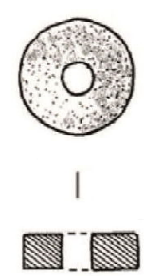

2
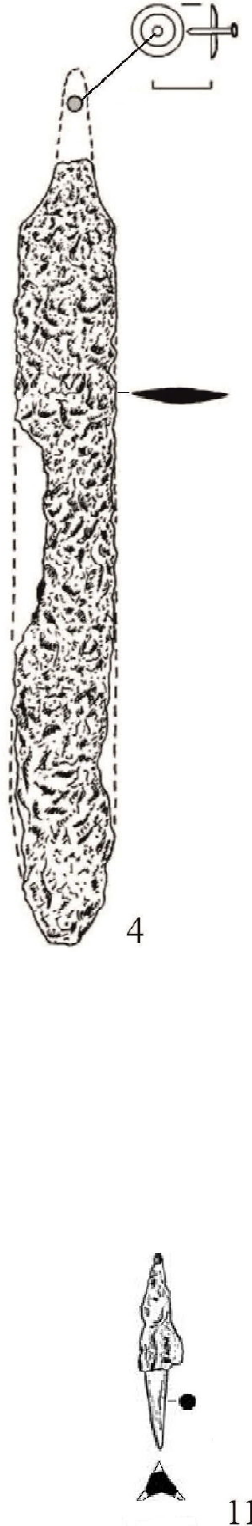
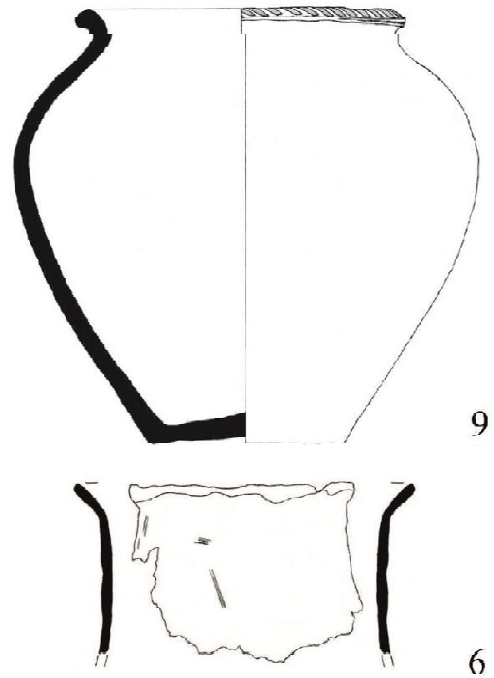

6
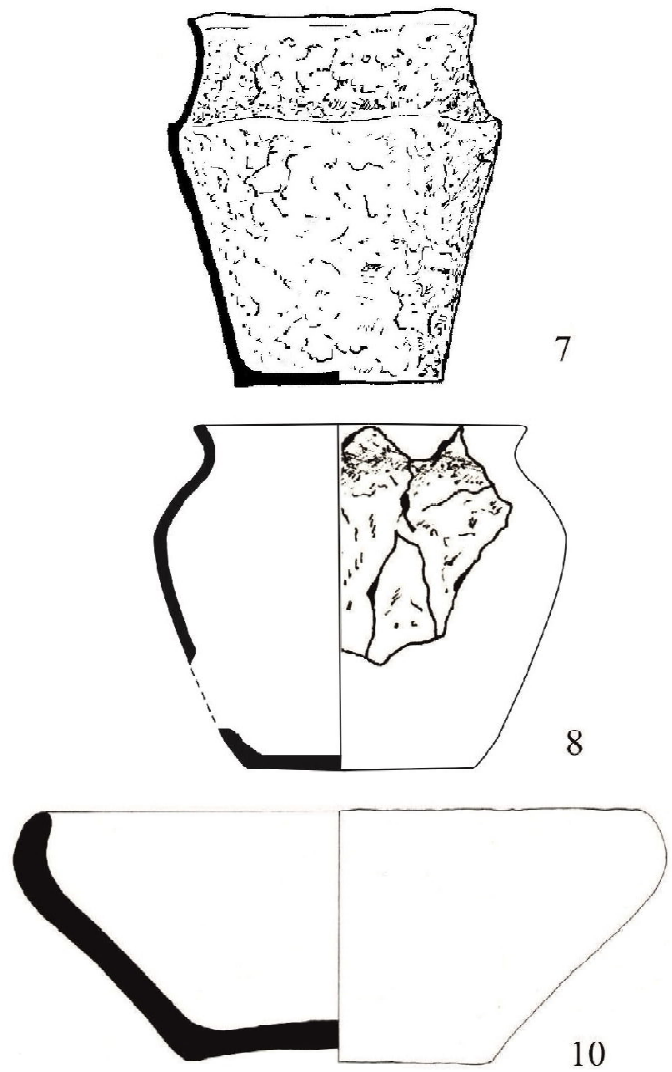

10

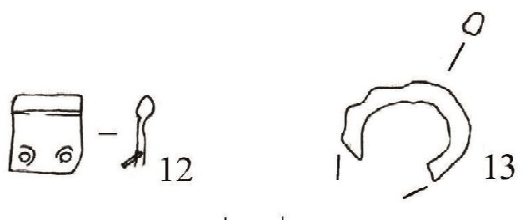

Рис. 6. Сопровождающий инвентарь из погребения в кургане 9 у с. Березовка:

1 - бронза; 2 - мел; 3-4, 11, 13 - железо; 5 - камень; 6, 10 - глина; 12 - серебро

Fig. 6. Grave goods from barrow burial 9 near the Berezovka village:

1 - bronze; 2 - chalk; $3,4,11,13$ - iron; 5 - stone; 6,10 - earthenware; 12 - silver 


\section{СПИСОК ЛИТЕРАТУРЫ}

1. Абрамова, М. П. Ранние аланы Северного Кавказа III-V вв. н. э. / М. П. Абрамова. - М. : ИА PAH, 1997. - $165 \mathrm{c}$.

2. Алексеева, Е. М. Античные бусы Северного Причерноморья / Е. М. Алексеева. - М. : Наука, 1982. - 105 с. - (САИ; вып. Г1-12).

3. Безуглов, С. И. Позднесарматские мечи (по материалам Подонья) / С. И. Безуглов // Сарматы и их соседи на Дону. - Ростов н/Д : Терра, 2000. С. 169-193.

4. Безуглов, С. И. Курганные катакомбные погребения позднеримской эпохи в нижнедонских степях / С. И. Безуглов // Проблемы современной археологии. - М. : Таус, 2008. - С. 284-301.

5. Березуцкий, В. Д. Погребение эпохи Великого переселения народов на Левобережье Среднего Дона / В. Д. Березуцкий, А. В. Мастыкова // КСИА. - 2016. - № 245-I. - С. 219-243.

6. Березуцкий, В. Д. Аланское погребение эпохи Великого переселения народов на Среднем Дону / В. Д. Березуцкий, А. П. Медведев // Российская археология. - 2015. - № 1. - С. 110-120.

7. Габуев, Т. А. Памятники ранних алан центральных районов Северного Кавказа / Т. А. Габуев, В. Ю. Малашев. - М. : Таус, 2009. - 468 с.

8. Засецкая, И. П. Материалы Боспорского некрополя второй половины IV - первой половины V в. н. э. / И. П. Засецкая // Материалы по археологии, истории и этнографии Таврии. - Вып. III. Симферополь : Таврия, 1993. - С. 23-104.

9. Малашев, В. Ю. Периодизация ременной гарнитуры позднесарматского времени / В. Ю. Малашев // Сарматы и их соседи на Дону. - Ростов н/Д : Teppa, 2000.-C. 194-232.

10. Малашев, В. Ю. Степное население Южного Приуралья в позднесарматское время : по материалам могильника Покровка 10 / В. Ю. Малашев, Л. Т. Яблонский. - М. : Восточная литература, 2008. -365 c.

11. Мастыкова, А. В. Женский костюм Центрального и Западного Предкавказья в конце IV середине VI в. н. э. / А. В. Мастыкова. - М. : ИА РAH, 2009. $-502 \mathrm{c}$.

12. Медведев, А. П. Опыт разработки региональной системы хронологии и периодизации памятников раннего железного века лесостепного Подонья / А. П. Медведев // Археология Центрального Черноземья и сопредельных территорий : тез. докл. науч. конф. - Липецк : Изд-во ЛГПУ, 1999. C. 17-21.

13. Медведев, А. П. Лесостепное Подонье накануне Средневековья / А. П. Медведев // Средневековые древности Дона : материалы и исследования по археологии Дона. - 2007. - Вып. 2. - С. 11-24.
14. Обломский, А. М. Этническая ситуация в лесостепном Подонье в позднеримское время / А. М. Обломский // Проблемы славянской археологии : тp.VI Междунар. конгресса славянской археологии. - М. : Изд-во НПО «Фонд археологии», 1997. - Т. 1. - С. 235-246.

15. Обломский, А. М. Материалы гуннского времени могильника Ксизово-17 / А. М. Обломский, И. А. Козмирчук // Острая Лука в древности. Археологический комплекс памятников гуннского времени у с. Ксизово (конец IV - V в.).- М. : ИА РАН, 2015. - С. 38-74. - (Раннеславянский мир ; вып. 16).

16. Обломский, А. М. Могильник гуннского времени Ксизово-19 / А. М. Обломский, И. А. Козмирчук // Острая Лука в древности. Археологический комплекс памятников гуннского времени у с. Ксизово (конец IV - V в.). - М. : ИА РАН, 2015. С. 134-164. - (Раннеславянский мир ; вып. 16).

17. Острая Лука в древности. Замятинский археологический комплекс гуннского времени. - М. : ИА РАН, 2004. - 330 с.- (Раннеславянский мир ; выП. 6).

18. Петраускас, О. В. Фібули «воїнського типу» черняхівської культури (за матеріалами пам'яток України) / О. В. Петраускас // Археологія Правобережної України. - Київ : ІА НАНУ, 2010. - С. 191-207.

19. Скрипкин, А. С. Нижнее Поволжье в первые века нашей эры / А. С. Скрипкин. - Саратов : Изд-во Сарат. ун-та, 1984. - 150 с.

20. Хреков, А. А. Древности Прихоперья / А. А. Хреков. - Балашов : Николаев, 2004. - 200 с.

\section{REFERENCES}

1. Abramova M. P. Rannie alany Severnogo Kavkaza III-V vv. n.e. [Early Alans of the North Caucasus in the $3^{\text {rd }}-5^{\text {th }} \mathrm{cc}$. AD]. Moscow, IA RAN Publ., 1997. 165 p.

2. Alekseeva E. M. Antichnye busy Severnogo Prichernomorya [Ancient Beads of the Northern Black Sea Region]. SAI [Corpus of Archaeological Sources]. Moscow, Nauka Publ., 1982, iss. G1-12. 105 p.

3. Bezuglov S.I. Pozdnesarmatskie mechi (po materialam Podonya) [Late Sarmatian Swords (Based on the Materials from the Don Region)]. Sarmaty $i$ ikh sosedi na Donu [Sarmatians and Their Neighbours on the Don]. Rostov-on-Don, Terra Publ., 2000, pp. 169-193.

4. Bezuglov S.I. Kurgannye katakombnye pogrebeniya pozdnerimskoy epokhi v nizhnedonskikh stepyakh [Barrow Catacomb Burials of the Late Roman Age in the Lower Don Steppes]. Problemy sovremennoy arkheologii, [The Issues of Modern Archaeology]. Moscow, Taus Publ., 2008, pp. 284-301. 
5. Berezutskiy V.D., Mastykova A. V. Pogrebeniye epokhi Velikogo pereseleniya narodov na Levoberezhye Srednego Dona [A Burial of the Migration Period on the Left Bank of the Middle Don]. KSIA [Brief Reports of the Institute of Archaeology], 2016, no. 245-I, pp. 219-243.

6. Berezutskiy V.D., Medevdev A.P. Alanskoe pogrebeniye epokhi Velikogo pereseleniya narodov na Srednem Donu [An Alanian Burial of the Migration Period in the Middle Don Region]. Rossiyskaya arkheologiya [Russian Archaeology], 2015, no. 1, pp. 110-120.

7. Gabuyev T. A., Malashev V.Yu. Pamyatniki rannikh alan tsentralnykh rayonov Severnogo Kavkaza [Early Alanian Sites in Central Regions of the North Caucasus]. Moscow, Taus Publ., 2009. 468 p.

8. Zasetskaya I.P. Materialy Bosporskogo nekropolya vtoroy poloviny IV - pervoy poloviny $\mathrm{V}$ v. n.e. [Materials of the Bosporan Necropolis of the Second Half of the $4^{\text {th }}-$ the First Half of the $5^{\text {th }} c c$. AD]. Materialy po arkheologii, istorii $i$ etnografii Tavrii [Materials on Archaeology, History and Ethnography of Tauria]. Simferopol, Tavriya Publ., 1993, iss. III, pp. 23-104.

9. Malashev V.Yu. Periodizatsiya remennoy garnitury pozdnesarmatskogo vremeni [Periodization of belt fittings of the Late Sarmatian age]. Sarmaty $i$ $i k h$ sosedi na Donu [Sarmatians and Their Neighbours on the Don]. Rostov-on-Don, Terra Publ., 2000, pp. 194-232.

10. Malashev V.Yu., Yablonsky L.T. Stepnoe naselenie Yuzhnogo Priuralya v pozdnesarmatskoe vremya: po materialam mogilnika Pokrovka 10 [The Steppe Population of the Southern Urals in the Late Sarmatian Time: Based on the Materials from the Burial Ground Pokrovka 10]. Moscow, Vostochnaya literatura Publ., 2008. 365 p.

11. Mastykova A.V. Zhenskiy kostyum Tsentralnogo i Zapadnogo Predkavkazya $v$ kontse $I V$-seredine VI v. n.e. [Women's Costume of Central and Western Regions of the North Caucasus in the Late $4^{\text {th }}-$ Middle $6^{\text {th }} \mathrm{cc}$. AD]. Moscow, IA RAN Publ., 2009. 502 p.

12. Medvedev A.P. Opyt razrabotki regionalnoy sistemy khronologii i periodizatsii pamyatnikov rannego zheleznogo veka lesostepnogo Podonya [Experimental Development of the Regional System for Chronology and Periodization of the Iron Age Sites in the Forest-Steppe Don Region]. Arkheologiya Tsentralnogo Chernozemya $i$ sopredelnykh territoriy: Tez. dokl. nauch. konf. [Archaeology of the Central Chernozem Region and Adjacent Territories. Theses of Reports of Academic Conference]. Lipetsk, Izd-vo LGPU, 1999, pp. 17-21.
13. Medvedev A.P. Lesostepnoe Podonye nakanune Srednevekovya [The Forest-Steppe Don Region on the Eve of the Middle Ages]. Srednevekovye drevnosti Dona: materialy i issledovaniya po arkheologii Dona [Don's Medieval Antiquities: Materials and Research on Don Archaeology], 2007, iss. II, pp. 11-24.

14. Oblomskiy A.M. Etnicheskaya situatsiya v lesostepnom Podonye v pozdnerimskoe vremya [Ethnic Situation in the Forest-Steppe Don Region in the Late Roman Age]. Problemy slavyanskoy arkheologii [Problems of Slavic Archaeology]. Moscow, Fond arkheologii Publ., 1997, vol. 1, pp. 235-246.

15. Oblomskiy A.M., Kozmirchuk I.A. Materialy gunnskogo vremeni mogilnika Ksizovo-17 [Materials of the Hunnic Age from the Burial Ground Ksizovo17]. Ranneslavyanskiy mir [The Ancient Slavic World]. Moscow, IA RAN, 2015, iss. 16, pp. 38-74.

16. Oblomskiy A.M., Kozmirchuk I.A. Mogilnik gunnskogo vremeni Ksizovo-19 [The Hunnic Age Burial Ground Ksizovo-19]. Ranneslavyanskiy mir [The Ancient Slavic World]. Moscow, IA RAN Publ., 2015a, iss. 16, pp. 134-164.

17. Ostraya Luka v drevnosti. Zamyatinskiy arkheologicheskiy kompleks gunnskogo vremeni [Ostraya Luka in Ancient Times. Zamyatino Archaeological Complex of the Hunnic Age]. Ranneslavyanskiy mir [The Ancient Slavic World]. Moscow, IA RAN Publ., 2004, iss. 6. 330 p.

18. Petrauskas O.V. 'Warrior-type' fibulae of the Chernyakhov culture (based on materials from the Ukrainian sites). Arkheologiya pravoberezhnoy Ukrainy [Archaeology of Right-Bank Ukraine]. Kiev, IA NANU Publ., 2010, pp. 191-207. (in Ukrainian).

19. Skripkin A. S. Nizhneye Povolzhye v pervye veka nashey ery [The Lower Volga Region in the First Centuries AD]. Saratov, Izd-vo SGU, 1984. 150 p.

20. Khrekov A. A. Drevnosty Prikhoperya [Antiquities of the Hoper Region]. Balashov, Nikolaev Publ., 2004. 200 p.

\section{СПИСОК СОКРАЩЕНИЙ}

ГосНИИР - Государственный научно-исследовательский институт реставрации.

ИА РАН - Институт археологии РАН.

КСИА - Краткие сообщения Институга археологии РАН.

ЛГПУ - Липецкий педагогический институт. НПО-Научно-производственное объединение. САИ - Свод археологических источников.

IА НАНУ - Институт археологии Национальной Академии наук Украины. 


\section{Information about the Authors}

Aleksandr P. Medvedev, Doctor of Sciences (History), Head of Department of Archaeology and Ancient History, Voronezh State University, Prosp. Moskovskiy, 88, 394052 Voronezh, Russian Federation, APM1950@yandex.ru, https://orcid.org/0000-0002-5160-2816

Valeriy D. Berezutskiy, Candidate of Sciences (History), Associate Professor, Voronezh State Pedagogical University, Lenina St., 84, 394043 Voronezh, Russian Federation, berezytski1@rambler.ru, https://orcid.org/0000-0001-8336-6283

\section{Информация об авторах}

Медведев Александр Павлович, доктор исторических наук, заведующий кафедрой археологии и истории древнего мира, Воронежский государственный университет, Московский просп., 88, 394052 г. Воронеж, Российская Федерация, APM1950@yandex.ru, https://orcid.org/0000-0002$5160-2816$

Березуцкий Валерий Дмитриевич, кандидат исторических наук, доцент, Воронежский государственный педагогический университет, ул. Ленина, 84, 394043 г. Воронеж, Российская Федерация, berezytski1@rambler.ru, https://orcid.org/0000-0001-8336-6283 